\title{
Student Editorial Board for Volume 29
}

Student Editorial Board members are appointed by members of the Editorial Board to serve for at least 1 year. Student members independently review manuscripts, which are also sent to their sponsoring board members. Participation on the board provides students with experience in the review process and provides authors of manuscripts with additional feedback. During the past year, the following students offered generously of their time to serve the journal as members of the Student Review Board. We are grateful for the contribution that each one has made to Law and Human Behavior.

Lucy Arnot, Department of Psychology, University of Nebraska at Lincoln Alison C. Cares, Department of Sociology, Pennsylvania State University Steven D. Charman, Department of Psychology, Iowa State University Shu-Ren Chang, Public Policy Center, University of Nebraska at Lincoln Sarah Greathouse, Department of Psychology, John Jay College of Criminal Justice Lisa E. Hasel, Department of Psychology, Iowa State University

Melanie Hazlehurst, Department of Psychology, University of Colorado at Colorado Springs

Katherine Hochevar, Department of Psychology, University of Colorado at Colorado Springs

Stacy N. Hoskins, Department of Sociology, Pennsylvania State University

Stephanie Mears, Department of Psychology, York University

Timothy Robicheaux, Department of Psychology, University of Nebraska at Lincoln

Ryan J. Winter, Department of Psychology, University of Nebraska at Lincoln 